\title{
Diversity In Analyst Coverage
}

Bruce C. Branson, (Email: bruce_branson@ncsu.edu), North Carolina State University

Donald P. Pagach, North Carolina State University

\begin{abstract}
This paper examines the effect of intra-industry "earnings informativeness" and proprietary firm information on variation in security analyst coverage within industries. Earnings informativeness is defined as the extent to which privately developed or obtained information about one firms' earnings provides useful information about the earnings of its industry co-members. Proprietary information provides signals concerning future firm profitability, relative to industry competitors, resulting from such factors as new product developments and innovations in production processes. The results reveal that levels of analyst coverage relative to mean levels of industry-specific analyst interest is significantly positively associated with intra-industry earnings informativeness and size-adjusted annual research and development expenditures (a proxy for proprietary firm information). The findings also show that certain determinants of analyst coverage (e.g., firm size and institutional ownership) identified in the prior literature as explaining variation in aggregate analyst following also hold at the industry level. Finally, the paper examines whether the model variables found to possess explanatory power within industries can also serve to explain observed variation in inter-industry levels of analyst interest and the results suggest that they can.
\end{abstract}

\section{INTRODUCTION}

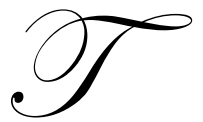

he purpose of this paper is to examine the effect of intra-industry "earnings informativeness" and proprietary firm information on variation in security analyst coverage within industries. Earnings informativeness is defined as the extent to which privately developed or obtained information about one firms' earnings provides useful information about the earnings of its industry co-members. The earnings informativeness proxy is computed as the average correlation between the earnings time-series of one firm and each of the other firms in the same three-digit SIC code industry. Proprietary information provides signals concerning future firm profitability resulting from such factors as new product developments and innovations in production processes. The degree of proprietary information possessed by the company is proxied by the amount of size-adjusted annual research and development (R\&D) expenditures of the firm relative to the industry-wide average of such expenditures.

We find that levels of analyst coverage relative to mean levels of industry-specific analyst interest is significantly positively associated with intra-industry earnings informativeness and size-adjusted annual research and development expenditures. We also find that certain determinants of analyst coverage identified in the prior literature as explaining variation in aggregate analyst following also hold at the industry level. Finally, we examine whether the model variables found to possess explanatory power within industries can also serve to explain observed variation in inter-industry levels of analyst interest and the results suggest that they can. ${ }^{1}$ These empirical findings are consistent with conjectures posed by King, Pownall, and Waymire (1990) with regard to security analyst coverage incentives.

This study extends research that provides evidence linking levels of and changes in aggregate analyst coverage to factors such as firm size, institutional ownership, market-adjusted returns, return variability, and industry affiliation. ${ }^{2}$ Schipper $(1991,105)$ remarks that:

Given their importance as intermediaries who receive and process financial information for investors, it makes sense to view analysts--sophisticated users--as representative of the group to whom financial reporting is and should be addressed. Under this perspective, accountants have a policy-based stake in understanding how analysts actually use financial information. 
The goal of this research is to provide additional evidence on this critical information flow by modeling intraindustry variation in analyst following as a function of earnings informativeness and firm-specific proprietary information. The model is expanded to include two control variables (firm size and institutional holdings) identified in prior research as significant determinants of analyst following to mitigate against model misspecification.

Three papers provide direct evidence linking firm-specific characteristics and analyst coverage; Bhushan (1989) models levels of analyst following (i.e., number of analysts) while O'Brien and Bhushan (1990) examine year-to-year changes in analyst following; Brennan and Hughes (1991) present evidence on both forms of the dependent variable. While this study includes certain explanatory variables from the above studies, it also omits certain variables found to be related to the extent of analyst following in order to focus on the King et al. conjectures. Given the nature of the earnings informativeness proxy--it is the average correlation among earnings time-series over a ten-year time period--the use of levels variables (as opposed to first differences) should not present a spurious correlation problem. The R\&D measure is both size-adjusted and standardized by the industry mean (for each industry) which should also mitigate against such concerns.

In the next section, we develop the tested hypotheses. In section three a descriptive profile of the sample firms follows a discussion of sample selection procedures. In the fourth section the results of the regression analyses along with a discussion of those findings is provided. Finally, the last section offers conclusions from the research.

\section{MODEL VARIABLES AND HYPOTHESES}

\section{Hypothesis Development}

Casual observation confirms that security analysts almost exclusively devote their research efforts to single industries (or closely related industry groups). Ostensibly, this narrow focus affords the analyst the opportunity to develop industry-specific expertise valuable in assessing the performance potential of the industry relative to market-wide movements. An unanswered question in the literature concerns the decision about which firm or firms in an industry are chosen for coverage. Empirical evidence presented herein portrays a marked disparity in coverage (ranging from 1 to 76 analysts, for example, in the Petroleum Refining industry (SIC code 291)) between intra-industry firms. This paper explores two potential determinants of the analysts' observed concentration on certain industry-member firms to the exclusion of others.

The number of analysts providing research attention to a given firm within an industry is expressed as a function of both earnings informativeness and the degree of proprietary information possessed by the firm relative to industry averages for these variables. Firm size and institutional holdings (also standardized by the average levels of these variables within the industry) are included in the model as control variables based on findings previously reported in the literature. In this section economic arguments are presented in support of the inclusion of each of these variables. Formal hypotheses are developed concerning the relationship between the dependent variable, relative analyst following, and earnings informativeness as well as proprietary information.

King, Pownall and Waymire (1990) characterize the role of the security analyst as an industry-specific information intermediary between firm management and capital markets. They observe that investors purchase analyst forecasts because the information they provide can be used to profitably trade. Competition among analysts, then, should ensure that more analysts follow those firms where the potential for such profits is greatest. Conversely, fewer analysts would be expected to follow firms where trading gains due to private information acquisition are difficult to realize. Two testable predictions are offered in King et al. that are of primary interest in this study.

The authors argue that since analysts should follow firms where potential trading gains are highest, "they should more actively follow those firms whose earnings convey the most information about other firms' earnings, and therefore generate the highest potential trading gains." (p.135) We develop a proxy for earnings informativeness to assess the accuracy of this hypothesis. A focus on earnings informativeness implies that analysts will concentrate their research efforts on firms for which private search activities reveal information concerning that firm plus other firms within the same 
industry. Limiting the informativeness measure to intra-industry firms is consistent with analysts' observed specialization by industry.

Earnings are an important information item analysts have at their disposal in forming expectations about the performance potential of the industry they cover. The application of research effort to gain "inside" knowledge of pending earnings surprises is best rewarded when such efforts are directed at firms whose past time-series of earnings have displayed a persistent correlation with the earnings series of other industry-member firms. Knowledge about earnings innovations for these firms can be readily applied to expectations of earnings for other industry-member firms.

Because such relations are imperfect and obscured by noise, analysts cannot merely focus on a single industry leader and expect to identify industry trends. Thus, we observe certain analysts covering many, if not all, of the firms within an industry. Nevertheless, concentrated attention on identified industry leaders allows for "low-cost" analysis of the other industry-member firms. While some analysts may follow all or most of the firms in an industry, others, with limited resources, will follow only those firms that provide information that is easily transferable to a broad set of industry comembers. Therefore, we should observe an above-average level of analyst interest in these firms. Hence, the first hypothesis (H1) can be stated as:

H1: The number of analysts following a firm is positively associated with that firms' earnings informativeness factor (EIF)--a measure of the degree to which that firm's earnings series provides information concerning other firms' earnings.

A second explanatory variable is also suggested by King, et al. They state that a major cost of public disclosure of information by firm management is associated with the release of proprietary data. They speculate that a firm possessing proprietary "good news" information will avoid losses due to forfeiture of competitive advantage through the use of an information intermediary, a security analyst.

Other avenues exist by which firm management can communicate "good news" without disclosure of the proprietary data. Share repurchase plans, dividend increases, and management earnings forecasts are all viable alternative mechanisms available to management to transmit "good news" to the market. Each of these alternatives, however, can result in costly future actions should the anticipated payoffs fail to materialize. For example, overly optimistic EPS forecasts by firm management can result in a loss of credibility and, possibly, shareholder litigation, while dividend increases and share repurchase plans require cash commitments that are costly to discontinue once initiated. ${ }^{3}$ In order to trade on the credibility of the analyst, firms will tend to disclose technological advances, product innovations, successful exploration efforts, etc. privately to analysts who subsequently disclose an earnings forecast and/or a buy/hold/sell recommendation without revealing the underlying proprietary information in order to preserve management relations. Costs associated with the public release of proprietary information will induce firm management to move away from public disclosure in favor of private disclosure through security analysts.

The level of research and development (R\&D) expenditures, relative to its industry co-members, should proxy for the magnitude of proprietary information possessed by a firm. Firms active in R\&D can be expected to generate more frequent product and process advances leading to competitive advantage. Thus, one should expect more analysts within an industry following those firms with relatively larger $\mathrm{R} \& \mathrm{D}$ expenditures in a given year. Hypothesis two (H2) is:

H2: The number of analysts following a firm is positively associated with size-adjusted R\&D outlays--a measure of the degree of proprietary information that a firm possesses.

\section{Control Variables}

Virtually all of the extant literature reports that firm size as measured by market value of common equity at some certain point in time (generally coincident to the measurement of analyst following) is a significant explanator of analyst following. Bhushan (1989) argues that benefits from private information acquisition are an increasing function of firm size. These increased benefits occur because larger firms, on average, experience larger trading volumes which better obscure 
information-based trades. This being so, the value of private information concerning these firms increases since the ability to trade profitably on it exists. Therefore, as firm size increases, so should analyst coverage. Based on Bhushan's empirical results, we expect a strong positive relation between relative analyst coverage and the market value of equity of a firm visà-vis the average-sized firm in that industry.

Bhushan (1989) also includes the percentage of a firms' shares held by institutions in his model. He reports a positive relation between analyst following and this ownership structure variable and argues that this occurs because institutional investors demand analyst recommendations to support their investment decisions. This naturally attracts analysts to those firms held largely by institutions. An alternative argument (also advanced by Bhushan) is that concentration of ownership by institutions could restrict the demand for analyst services by reducing the total number of investors in that stock. Notwithstanding Bhushan's findings, this is an equally compelling argument and accordingly we make no predictions concerning the sign of the association (if any). The next section discusses sample selection procedures and presents descriptive statistics of the sample firms.

\section{SAMPLE SELECTION AND DESCRIPTIVE PROFILE}

The sample is comprised of all firms listed on the 1989 quarterly Compustat Expanded and Full Coverage files with complete data for the following items: (1) An uninterrupted time-series of forty quarterly earnings observations (earnings before extraordinary items) in the time period 1979-1988 (no restriction need be placed on fiscal year-end because no cross-sectional modeling is conducted), ${ }^{4}$ (2) book value of total assets, (3) number of common shares outstanding, and (4) share price, all at year-end. Annual research and development expense is available on the relevant version of the 1989 annual Compustat tape. ${ }^{5}$ Sample acquisition data is presented in Table 1. The sample is dominated by NYSE firms (78.5\% of the total) with the remaining firms distributed between the AMSE (15.5\%) and the NASDAQ market $(6.0 \%)$.

Table 1

Primary Sample Acquisition

Reason For Deletion

Forty consecutive quarters of earnings data in 1979-1988

Less: $\quad$ Missing or unavailable data for:

Market value of equity

Book value of total assets

R\&D expense

Institutional holdings

Dual listing on 1990 Tertiary and Full Coverage tapes

Change in fiscal year-end 1979-1989

Restricted industry membership (3-digit SIC code industry contains less than 4 firms)
Number Of Observations

1252

20

328

90

25

71

184

Sample

$\underline{\underline{523}}$

The dependent variable (number of analysts following a given firm) and the data related to institutional holdings were collected from the 1989 edition of Nelson's Directory of Investment Research. Nelson's provides company profiles, analyst coverage information (individual and firm) and research report dates for over 7800 U.S. and foreign companies. ${ }^{6}$ This appears to be a superior source for analyst coverage information vis-à-vis a frequently substituted alternative--the number of analysts supplying earnings forecasts to the Institutional Brokers' Estimate System. Nelson's covers a broader set of companies and includes analysts who not only forecast earnings but others who render buy/hold/sell recommendations or publish research reports without publicly disclosing an earnings prediction.

A proxy for earnings informativeness is computed for each firm in 1988. The informativeness variable measures the degree to which one firm's earnings reveals information relevant to assessing the earnings of other firms within that 
industry. The information transfer literature does not directly suggest a useful proxy for this concept. ${ }^{7}$ The position of firm A in the "earnings announcement queue" of that industry does not reveal useful information regarding the relative informativeness of firm A's earnings. For example, even if firm A is a late-releaser, foreknowledge of its earnings (from private information search activities) may provide useful trading information relevant to other firms (even those whose actual earnings announcement precedes firm A's).

The literature on intra-industry information transfers has focused on examining the relationship of one firm's earnings with other intra-industry firms. Pyo and Lustgarten (1990) investigate information transfers that result from management forecasts of earnings and demonstrate that such transfers are dependent upon the variance of the earnings series of the examined firm and the covariance of that firm's earnings with the earnings of a second firm within the industry. We compare the comovement of earnings of a single firm with all other intra-industry firms. Freeman and Tse (1992) provide results indicating that the extent of information transfer that occurs varies cross-sectionally by industry. This study extends Freeman and Tse by investigating intra-industry variation in potential information transfer--what we term earnings informativeness. $^{8}$

Earnings informativeness is proxied by the mean absolute value of Spearman rank correlations of firm A's 40quarter earnings series to all the other firms', within firm A's three-digit SIC code industry, earnings. The historical relation between the earnings of one firm and the earnings of its intra-industry competitors can be positive or negative depending upon many factors. One such factor is the age of the firm relative to the industry. It seems reasonable to expect the earnings of nonmature companies, with small market shares, to correlate directly with larger industry co-members. On the other hand, for industries with more than one large, "dominant" firm, we might expect the earnings of such firms to be negatively correlated as they compete for sales and market share. This is especially likely in mature and declining industries.

We argue that negative correlation (which is observed empirically in the sample) is equally as informative to analysts and, thus, the absolute values of the correlations between pairs of firms are summed and averaged to obtain the firm-specific EIF. For example, in a 10-firm industry, firm A's EIF would be computed as the sum of the unsigned Spearman rank correlations between its 40-quarter earnings time-series and the earnings series of each of the other nine industry-member firms. This sum is then divided by nine. In order to make the informativeness measure meaningful, at least four firms must be a member of a specific industry. ${ }^{9}$

Panel A of table 2 contains the EIF's for the Computer Programming and Data Processing industry (SIC code 737). Six firms from this industry are represented in the final sample. Panel B displays the underlying correlations between the earnings time-series for these firms. As discussed above, negative correlation between earnings series is observed empirically. In this industry, for example, the earnings of firm D, Datapoint Corp., are negatively correlated with the earnings of all of its industry competitors. Firm F, Titan Corp., also displays a negative earnings correlation with four of its five co-members. This industry was chosen for illustrative purposes and is generally representative of the correlations observed among firms in each of the 76 industries in the sample.

In table 3 a descriptive profile of the sample is provided. In panel A, mean, standard deviation, median and range values for the dependent variable--analyst following--and the independent variables (market value of equity, institutional holdings, earnings informativeness, and annual research development expenditures (deflated by book value of total assets)) are presented. Panel B contains similar information for the transformed variables that enter the regression model. This research explores intra-industry variation in analyst following, hence, the transformation is designed to control for interindustry differences in the level of analyst coverage that have been documented by Bhushan (1989) and O'Brien and Bhushan (1990). We standardize the dependent variable and each of the independent regressors by subtracting the industry-specific mean for each of these variables from the firm-specific data.

In table 4, Pearson and Spearman rank correlations among these standardized model variables are provided. Univariate correlations between the dependent variable, relative number of analysts (NANL), and each of the independent variables are positive and statistically significant. Correlations between the independent variables are also significant in 
most paired comparisons but at generally lower levels. The effect of multicollinearity on the parameter estimates in the multivariate regressions is addressed in a later section along with other diagnostic checks.

Table 2

Earnings Informativeness In The Computer Programming And Data Processing Industry (Sic Code 737)

Panel A - Earnings Informativeness Factors (EIF's)

\begin{tabular}{lc}
\hline Company Name & EIF \\
Automatic Data Processing & .49516 \\
Bolt, Beranek \& Newman, Inc. & .41242 \\
Comdisco, Inc. & .45632 \\
Datapoint Corp. & .43080 \\
Recognition Equipment, Inc. & .26413 \\
Titan Corp. & .17231 \\
\hline
\end{tabular}

Panel B - Earnings Correlation Matrix For Computation Of EIF's

\begin{tabular}{llllll}
\hline & Firm B & Firm C & Firm D & Firm E & Firm F \\
Firm A & .6872 & .8068 & -.5533 & .2662 & -.1623 \\
Firm B & & .5372 & -.5705 & .2390 & -.0281 \\
Firm C & & -.6368 & .1831 & -.1178 \\
Firm D & & & -.2362 & -.1572 \\
Firm E & & & & .3961 \\
\hline
\end{tabular}

Firms are identified as follows: Firm A: Automatic Data Processing, Firm B: Bolt, Beranek \& Newman, Inc., Firm C:Comdisco, Inc., Firm D:Datapoint Corp.,Firm E: Recognition Equipment, Inc., and Firm F: Titan Corp.

\section{MULTIVARIATE TESTS AND RESULTS OF ANALYSES}

\section{The Regression Model}

The multiple regression model used to assess the degree of association between relative analyst following and the independent variables is:

$\mathrm{NANL}_{\mathrm{i}}=\beta_{0}+\beta_{1} \mathrm{LMV}_{\mathrm{i}}+\beta_{2} \mathrm{INST}_{\mathrm{i}}+\beta_{3} \mathrm{EIF}_{\mathrm{i}}+\beta_{4} \mathrm{RD}_{\mathrm{i}}+\varepsilon_{\mathrm{i}}$

where $\mathrm{NANL}_{\mathrm{i}}$ is the number of security analysts following firm $\mathrm{i}, \mathrm{LMV}_{\mathrm{i}}$ is the natural logarithm of the year-end market value of equity of firm $\mathrm{i}, \mathrm{INST}_{\mathrm{i}}$ is the percentage of shares outstanding held by institutional investors, $\mathrm{EIF}_{\mathrm{i}}$ is the earnings informativeness factor for firm $\mathrm{i}, \mathrm{RD}_{\mathrm{i}}$ is the level of research and development expenditures for firm $\mathrm{i}$ deflated by the yearend book value of total assets, and $\varepsilon_{\mathrm{i}}$ is an independent, normally-distributed error term. As discussed earlier, each of these variables are adjusted by their industry-specific means before entering the regression.

\section{Discussion Of Results}

The prediction that analysts will concentrate their attention on those firms whose earnings are most informative (H1) is supported by the regression results provided in table 5. Heteroskedasticity is indicated (from the test developed by White [1980]), therefore, t-statistics computed using the heteroskedasticity-consistent covariance matrix are provided and are the basis for all inferences in the following discussions. The earnings informativeness proxy, EIF, is found to be significantly associated with relative analyst following in the predicted positive direction. This finding is consistent with the notion that analysts have identified those firms whose earnings provide useful signals concerning the earnings of other industry-member firms. As discussed earlier, concentration of effort on these types of firms is most valuable to the analyst community because the potential for private trading gains is magnified when such effort yields some knowledge about future earnings. This occurs primarily from analyst trading activity in the shares of the group of firms whose unexpected earnings are partially revealed by this private knowledge. ${ }^{10}$ The results are consistent with this interpretation. 
Table 3

Panel A - Raw Data

Profile Of Sample

\begin{tabular}{llllll} 
Variable & Mean & Std.Dev. & Median & Min & Max \\
NANL & 17.44 & 14.98 & 13.00 & 1.00 & 76.00 \\
LMV & 6.33 & 1.79 & 6.35 & 1.82 & 11.18 \\
INST & 41.99 & 18.80 & 44.00 & 1.00 & 79.00 \\
EIF & 0.37 & 0.16 & 0.34 & 0.07 & 0.76 \\
RD & 0.02 & 0.03 & 0.01 & 0.00 & 0.16 \\
\hline
\end{tabular}

Panel B - Standardized Data

$\begin{array}{llllll}\text { Variable } & \text { Mean } & \text { Std.Dev. } & \text { Median } & \text { Min } & \text { Max } \\ \text { NANL } & 0.00 & 11.47 & -1.17 & -36.54 & 38.46 \\ \text { LMV } & 0.00 & 1.44 & -0.01 & -4.91 & 4.16 \\ \text { INST } & 0.00 & 16.52 & 1.33 & -48.00 & 42.35 \\ \text { EIF } & 0.00 & 0.09 & 0.01 & -0.38 & 0.18 \\ \text { RD } & 0.00 & 0.02 & -0.00 & -0.09 & 0.08\end{array}$

Note: 523 observations. Panel A contains untransformed data. Panel B contains the same data after subtracting the industry-specific mean values for each variable from the firm-specific observations. Variable definitions are as follows: NANL is the number of security analysts following a firm in 1988. LMV is the natural log of the market value of equity on December 31, 1988 in millions of dollars. INST is the percentage of firm shares held by institutional investors. EIF is the earnings informativeness factor and is computed as the average absolute value of the (Spearman rank) correlation of one firm's earnings series (forty consecutive quarters from 1979-88) with the earnings of each of its industry co-members. Industry membership is determined by three-digit SIC code classifications. RD is the amount of annual research and development expenditures deflated by book value of total assets on December 31, 1988.

Table 4

Correlation Matrix For Model Variables

\begin{tabular}{llllll}
\hline VAR & NANL & LMV & INST & EIF & RD \\
NANL & 1.0000 & 0.8323 & 0.4377 & 0.3121 & 0.2523 \\
& & 0.0001 & 0.0001 & 0.0001 & 0.0001 \\
LMV & 0.8387 & 1.0000 & 0.4782 & 0.3003 & 0.1637 \\
& 0.0001 & & 0.0001 & 0.0001 & 0.0002 \\
INST & 0.4754 & 0.4812 & 1.0000 & 0.1695 & 0.1577 \\
& 0.0001 & 0.0001 & & 0.0001 & 0.0003 \\
EIF & 0.3081 & 0.2958 & 0.1635 & 1.0000 & 0.0158 \\
RD & 0.0001 & 0.0001 & 0.0002 & & 0.7184 \\
& 0.2857 & 0.2054 & 0.1493 & 0.0404 & 1.0000 \\
\hline
\end{tabular}

Note: 523 observations. The upper diagonal of the correlation matrix contains Pearson product-moment correlations. The lower diagonal contains Spearman rank correlations. Variable definitions are as follows: NANL is the number of security analysts following the firm in 1988. LMV is the natural $\log$ of the market value of equity on December 31, 1988 in millions of dollars. INST is the percentage of firm shares held by institutional investors. EIF is the earnings informativeness factor and is computed as the average absolute value of the (Spearman rank) correlation of one firm's earnings series (forty consecutive quarters from 1979-88) with the earnings of each of its industry co-members. Industry membership is determined by three-digit SIC code classifications. RD is the amount of annual research and development expenditures deflated by book value of total assets on December 31, 1988. Each of these variables are transformed by subtracting their industry-specific mean values from the firm-specific observations. The second number reported under each correlation coefficient is the probability that that correlation is equal to zero. 
Table 5

Intra-Industry Variation In Analyst Following

$\mathrm{NANL}=\beta_{0}+\beta_{1}$ LMV $+\beta_{2}$ INST $+\beta_{3}$ EIF $+\beta_{4}$ RD $+\varepsilon$

\begin{tabular}{|c|c|c|c|}
\hline Variable & Coefficient & T-Stat & White's T-Stat \\
\hline Intercept & $-1.58 \mathrm{E}-16$ & -0.00 & -0.00 \\
\hline LMV & 6.18 & 27.73 & $21.64^{*}$ \\
\hline INST & 0.03 & 1.37 & 1.09 \\
\hline EIF & 8.73 & 2.90 & $2.78^{*}$ \\
\hline $\mathrm{RD}$ & 63.99 & 4.95 & $4.89^{*}$ \\
\hline
\end{tabular}

Nobs 523, Adjusted $\mathrm{R}^{2} .7101$, F-stat $320.71^{*}$, White's test $24.61(\mathrm{p}<.039)$. Variable definitions as described in the notes to table 4.

${ }^{*}$ indicates significance at $\mathrm{p}<.01$.

Hypothesis two is also supported by the regression findings. H2 concerns the likelihood that a firm's management will release information either directly to the market or indirectly through conversations with security analysts. It was argued that as the amount of proprietary information a firm possesses increases so does the probability that management will choose the indirect path of information disclosure. As suggested by King et al., annual research and development $(R \& D)$ expense is used as a proxy for proprietary information. The relative amount of $R \& D$ expenditures, deflated by book value of total assets, compared to other industry co-members, is significantly associated with the level of relative analyst following in the predicted positive direction.

Consistent with prior research, firm size was found to be positively associated with the level of analyst following. Regression results in table 5 show this relationship to be statistically significant at the $p<.001$ level. As discussed previously, this finding is generally supportive of the notion that the increased trading opportunities afforded by large capitalization firms is a powerful draw to the analyst community. Private trading information (e.g., some foreknowledge about the nature of an upcoming earnings surprise) can best be exploited in trades that might be mistaken for liquidity motivated behavior. For those companies with large market capitalizations, the size of these information-based trades can be increased.

The evidence presented in table 5 does not support the findings of Bhushan (1989) with respect to the effect of increased institutional holdings on security analyst interest. Specifically, we find an insignificant association between relative analyst following and institutional holdings relative to the average holdings within an industry. From Bhushan's arguments, one might assume that the additional demand for analyst services associated with institutional factors (such as "prudent man" investment rules) is balanced by the concentration of ownership in fewer hands (which may cause downward pressure on total demand for analyst outputs).

\section{Diagnostic Checks}

Inspection of table 4 suggests that multicollinearity is a potential threat to the validity of inferences drawn from the regression results. In the presence of multicollinearity, estimates of standard errors are typically inflated which can lead to incorrect conclusions regarding significance levels of the parameter estimates. Regression diagnostics are used to identify condition indices for each estimated coefficient. The reported indices range in value from 1.00 to 1.85 . This indicates that multicollinearity is not a threat to valid inference. The effect of outliers was assessed using the INFLUENCE option in the SAS regression procedure. No observations with values of DFFITS (from Belsey, Kuh, and Welsch [1980]) exceeding one were identified.

In other specification tests, the model was first re-estimated using data relevant to 1989. Specifically, the dependent variable, NANL, and all independent variables were obtained in a manner analogous to the data acquisition procedures previously discussed. For example, the analyst coverage data was collected from the 1990 edition of Nelson's Directory of Investment Research (which identifies research coverage in 1989) and the firm-specific earnings informativeness factors were recalculated using updated earnings data through 1989. The results of this re-estimation mirror the reported results in table 5. Second, a regression of ranked values of the dependent variable on the matrix of 
independent variable ranks provided the following results. Variation in the rank of relative analyst following was significantly positively associated with each of the explanatory variables including (ranked values of) institutional holdings. This regression had an adjusted $\mathrm{R}^{2}$ of .725 . Additional details of these tests are available from the authors.

\section{Earnings Informativeness At The Industry Level}

This paper has focused on explaining intra-industry variation in analyst coverage. This section briefly explores a second question--explaining inter-industry differences in analyst following. The earnings informativeness factor (EIF) was developed on an industry-by-industry basis, comparing one firm's earnings series to the earnings of its industry comembers. O'Brien and Bhushan (1990) document an industry effect in explaining changes in analyst coverage from one year to the next. One possible explanation for industry concentration among analysts is that certain industries may be more amenable to research and performance forecasting by virtue of increased levels of correlation among its members. Schipper $(1990,105)$ notes that "analysts' behavior appears to be predicated on the assumption of within-industry information transfers." Hence, one would expect to find more analysts concentrated in those industries where such transfers are most readily observed.

To examine this issue, untransformed median values of analyst following (MDNANL), logged market value (MDLMV), institutional holdings (MDINST), earnings informativeness (MDEIF), and size-adjusted R\&D expenditures (MDRD) for each of the 76 three-digit SIC code industries in the final sample were collected. An additional variable--the number of sample companies within each industry (NUM)--was added as a control for an obvious source of inter-industry variation in analyst coverage. The following model was employed:

MDNANL $=\beta_{0}+\beta_{1}$ NUM $+\beta_{2}$ MDLMV $+\beta_{3}$ MDINST $+\beta_{4}$ MDEIF $+\beta_{5}$ MDRD $+\varepsilon$

The results, reported in table 6, reveal that the median level of analyst attention devoted to each industry is significantly associated with the median size of industry firms, the median level of earnings informativeness possessed by firms within that industry, and the median level of size-adjusted R\&D expenditures (all positive). We also find a positive association between median analyst interest in an industry and the number of sample firms in that industry (significant at $\mathrm{p}<.10$ ). Finally, we find no association between MDNANL and the median level of institutional holdings per industry. These results support the notion that analysts are attracted to industries where "economies of scale" in information acquisition are possible. That is, analysts seem to concentrate attention on those industries where private knowledge concerning one or a small group of firms allows for accurate inferences to be drawn with respect to the remaining firms in that industry.

Table 6

Inter-Industry Variation In Analyst Following

MDNANL $=\beta_{0}+\beta_{1}$ NUM $+\beta_{2}$ MDLMV $+\beta_{3}$ MDINST $+\beta_{4}$ MDEIF $+\beta_{5}$ MDRD $+\varepsilon$

\begin{tabular}{lccc}
\hline Variable & Coefficient & T-Stat & White's T-Stat \\
Intercept & -30.69 & -9.13 & -8.48 \\
NUM & 0.36 & 2.49 & 1.80 \\
MDLMV & 6.30 & 10.43 & $10.14^{*}$ \\
MDINST & -0.05 & -0.72 & -0.74 \\
MDEIF & 10.11 & 2.26 & $2.14^{* *}$ \\
MDRD & 88.18 & 2.64 & $2.50^{* *}$ \\
\hline
\end{tabular}

Nobs 76, Adjusted R $\quad .7304$, F-stat $\quad 41.65^{*}$, White's test $749.03(\mathrm{p}<.0001)$.

${ }^{*}$ indicates significance at $\mathrm{p}<.01,{ }^{* *}$ indicates significance at $\mathrm{p}<.05$. Variable definitions are as follows: MDNANL is the median number of security analysts that follow the firms in a specific industry. NUM is the number of sample firms within an industry.

MDLMV is the median logged market value of all firms within a given industry. MDINST is the median percentage of outstanding shares held by institutional investors for all firms in a particular industry. MDEIF is the median level of "earnings informativeness" as derived in the paper. MDRD is the median level of size-adjusted research and development expenditures for firms within a specific three-digit SIC code industry. 


\section{CONCLUSIONS}

This paper investigates intra-industry variation in analyst interest. To control for inter-industry differences in analyst coverage, each of the examined variables are standardized by their industry-specific mean values. This allows for pooling across industries in the cross-sectional regression model employed in this research. Analysts specialize in specific industries and, purportedly, develop expertise in these areas of specialization. This research identifies factors associated with the choice of certain industry-member firms for coverage to the exclusion of others. Those firms that receive "abnormal" analyst attention vis-à-vis their industry co-members are relatively larger firms whose earnings provide useful signals about the earnings of other industry-member firms. Those companies with higher levels of size-adjusted R\&D expenditures relative to the industry average also draw increased analyst attention.

Analysts tend to concentrate their scarce research efforts on those firms within an industry that provide timely signals on the earnings prospects (or, more generally, future performance) of as many industry-member firms as possible. An "earnings informativeness" measure was developed to test this hypothesis. Specifically, an earnings informativeness factor (EIF) was computed for each firm as the mean (absolute) correlation between its earnings series and each of its industry co-member's earnings series. A high level of correlation indicates that efforts expended in uncovering private information about such a firm's upcoming earnings announcement are rewarded by increased trading opportunities in many other industry-member firms. The empirical evidence supports this argument. EIF is significantly positively associated with relative analyst following--consistent with the idea that such firms attract increased analyst attention relative to their industry co-members.

The second hypothesis involves the disincentives faced by firm management when public disclosure of an earnings forecast might prove costly to the firm. Costly disclosure occurs when public release reveals proprietary information to competitors, thus causing a forfeiture of competitive advantage. As the level of proprietary information increases, so does the likelihood that firm management will choose an indirect route of information release. King et al. (1990) argue that this increased desire of management to utilize information intermediaries will attract analysts to that firm.

The empirical evidence is generally supportive of this hypothesis. As relative R\&D expenditures increase, it is reasonable to assume that an above-average level of product and process innovations, compared to industry competitors, will result. These innovations give rise to hard-won competitive advantages that firms are (rightly) reluctant to forfeit, thus motivating private communications with security analysts. Relative annual R\&D expense (deflated by book value of total assets) is positively associated with relative analyst following. Firm size, measured by logged market value of equity, was found to be significantly associated with relative analyst interest in the predicted positive direction consistent with the findings of prior research. Finally, an insignificant association between relative analyst following and institutional holdings was identified.

Consistent with the firm-specific results that document an association between intra-industry analyst following and three of the four independent regressors, the median level of analyst following by industry was found to be positively associated with the median size, earnings informativeness, and size-adjusted R\&D expenditures of firms, by industry, across 76 three-digit SIC code industries. An additional explanatory variable, the number of sample firms within each industry, was also found to be positively associated with analyst coverage at the industry level.

\section{Suggestions For Future Research}

King et al. (1990) suggest alternative proxies for the measurement of information transfer which would provide corroborative evidence supporting the findings in this study. In addition to cross-correlation in earnings, the authors state that cross-correlation in returns might be used to identify "dominant" firms within an industry that should receive increased analyst attention. King et al. also suggest product market shares as a potential measure of dominance. Pyo and Lustgarten (1990) operationalize an informativeness measure in their investigation of information transfers associated with management earnings forecasts similar to the proxy used in this research. Their measure utilizes the earnings covariance between two firms unlike the broader industry-based measure developed in this study. 
The earnings informativeness measure used in this research identified numerous occasions where the earnings series' of two intra-industry firms displayed negative correlation. Additional research might profitably explore the economic determinants of such occasions. Evidence on the nature and extent of such relations, as might exist, would provide useful insight into intra-industry dynamics and analyst behavior.

This research provides corroborative evidence for several interesting conjectures posed by King et al. and augments the work of Bhushan (1989), O'Brien and Bhushan (1990), and Brennan and Hughes (1991) by examining intraindustry variation in analyst following. Knowledge of the linkage between firm management, information intermediaries (security analysts), and capital markets is an important determinant in our ability to fully appreciate the speed and accuracy of the information flow that drives firm value. As Schipper has noted, our understanding of the analyst community is an integral component in that knowledge base.

\section{ENDNOTES}

1. The phrase "analyst interest" is used often in the paper and is meant to be synonymous with analyst following/coverage.

2. $\quad$ See Bhushan (1989), O'Brien and Bhushan (1990), and Brennan and Hughes (1991).

3. The extent to which firm management avails themselves of these opportunities will bias against finding the predicted association unless one views these alternative information dissemination mechanisms as indicative of proprietary information. In that case, we would expect them to arouse analyst interest.

4. $\quad$ Firms that changed fiscal year-end's during the sample period are not included.

5. This item is not available for banks, utilities, life insurance or property and casualty companies. For sample companies in other industries, $R \& D$ expense is assumed to equal zero if unavailable. To assess the sensitivity of this assumption, the main tests were repeated omitting those firms with missing data for R\&D. The reported results were not materially affected.

6. $\quad$ For additional discussion of Nelson's Directory, see Bhushan (1989).

7. See, for example, Foster (1981), Baginski (1987), and Freeman and Tse (1992).

8. A "global" measure of industry informativeness could be obtained by calculating the Kendall coefficient of concordance. In this study, however, intra-industry variation in the informativeness criterion is the focus in order to investigate firm-specific analyst interest.

9. The EIF was computed using the sample of firms with the necessary earnings data and industry membership. Data on institutional holdings and R\&D expenditures was not a criteria for this computation. Hence, 941 firm observations (92 industries) were used in this step.

10. Analysts need not participate directly in the market in order for this effect to occur. By selling private information to paying clients, the analyst maximizes his/her income by first notifying those clients willing to pay a premium for this information. Once traded upon, the new information becomes less valuable as the market observes a consistent trading pattern. Abdel-khalik and Ajinkya (1982) provide additional discussion concerning institutional aspects of information dissemination by analysts.

\section{REFERENCES}

1. Abdel-khalik, A. and B. Ajinkya. 1982. Returns to Informational Advantages: The Case of Analysts' Forecast Revisions. The Accounting Review (October): 661-680.

2. Baginski, S. P. 1987. Intraindustry Information Transfers Associated with Management Forecasts of Earnings. Journal of Accounting Research (Autumn): 196-216.

3. Belsey, D. A., E. Kuh, and R. E. Welsch. 1980. Regression Diagnostics: Identifying Influential Data and Sources of Collinearity. New York, NY: John Wiley \& Sons.

4. Bhushan, R. 1989. Firm Characteristics and Analyst Following. Journal of Accounting and Economics 11: 255-274.

5. Brennan, M. J. and P. J. Hughes. 1991. Stock Prices and the Supply of Information. Journal of Finance 46: 1665-1695. 
6. Freeman, R. and S. Tse. 1992. An Earnings Prediction Approach to Examining Intercompany Information Transfers. Journal of Accounting and Economics 15: 509-523.

7. Foster, G. 1981. Intra-Industry Information Transfers Associated with Earnings Releases. Journal of Accounting and Economics 3: 201-232.

8. King, R., G. Pownall, and G. Waymire. 1990. Expectations Adjustment Via Timely Management Forecasts: Review, Synthesis, and Suggestions for Future Research. Journal of Accounting Literature 9: 113-144.

9. Nelson's Directory of Investment Research. 1989, 1990. New York: Nelson Publications.

10. O'Brien, P. C. and R. Bhushan. 1990. Analyst Following and Institutional Ownership. Journal of Accounting Research 28 (Supplement): 55-76.

11. Pyo Y. and S. Lustgarten. 1990. Differential Intra-Industry Information Transfer Associated With Management Earnings Forecasts. Journal of Accounting and Economics 13: 365-379.

12. SAS Institute Inc. 1990. SAS User's Guide: Statistics, Version 6 Edition. Cary, NC: SAS Institute, Inc.

13. Schipper, K. 1991. Analysts' Forecasts. Accounting Horizons (December): 105-121.

14. White. H. 1980. A Heteroskedasticity-Consistent Covariance Matrix Estimator and a Direct Test for Heteroskedasticity. Econometrica 4: 817-838. 